\title{
Cianobactérias e algas reduzem os sintomas causados por Tobacco vosaic virus (TMV) em plantas de fumo
}

\author{
André B. Beltrame ${ }^{1} \&$ Sérgio Florentino Pascholati ${ }^{2}$
}

Departamento de Fitopatologia e Nematologia, ESALQ/USP, C.P. 9, CEP 13418-900, Piracicaba, SP; ${ }^{1}$ Bolsista FAPESP; ${ }^{2}$ Bolsista CNPq. Parte da Dissertação de Mestrado do Primeiro autor.

Autor para correnpondência: Sérgio F. Pascholati (sfpascho@esalq.usp.br)

Data de chegada: 29/01/2008. Aceito para publicação em: 20/09/2010.

\section{RESUMO}

Beltrame, A.B. \& Pascholati, S.F. Cianobactérias e algas reduzem os sintomas causados por Tobacco mosaic virus (TMV) em plantas de fumo. Summa Phytopathologica, v.37, n.2, p.140-145, 2011.

\begin{abstract}
As algas e as cianobactérias produzem uma grande diversidade de compostos com atividade biológica direta sobre microrganismos ou agem como ativadores de mecanismos de resistência em plantas. Em vista disso, foi investigada a manifestação dos sintomas causados pelo Tobacco mosaic virus (TMV) em plantas de fumo previamente tratadas com cianobactérias ou algas. Quando as folhas plantas de fumo foram tratadas dois dias antes da inoculação, foi verificado que suspensões de células dos isolados de cianobactérias 004/02, 008/02, Anabaena sp. e Nostoc sp. 61; e do isolado de alga 061/02, bem como
\end{abstract}

as preparações do conteúdo intracelular do isolado 004/02 (4 C) e do filtrado do meio de cultivo do isolado 061/02 (61 M) apresentaram efeito na redução do número de lesões locais provocadas por TMV em folhas de plantas fumo, cultivar TNN. Além disso, foi observado que os isolados Anabaena sp., Nostoc sp. 21 (cianobactéria), Nostoc sp. 61 e 090/02 (alga) mostraram efeito direto sobre o vírus semi-purificado. Em vista disso, pode-se sugerir que os isolados estudados sintetizam compostos que agem diretamente sobre o TMV e/ou ativam o mecanismo de defesa de plantas contra fitopatógenos.

Palavras-chave adicionais: controle biológico e indução de resistência.

\begin{abstract}
Beltrame, A.B. \& Pascholati, S.F. Cyanobacterias and algae reduce symptoms caused by Tobacco mosaic virus (TMV) in tobacco plants. Summa Phytopathologica, v.37, n.2, p.140-145, 2011.

Algae and cyanobacterias produce several different compounds with biological activity against microorganisms as well as inducers of the mechanisms of plant defense. Thus, the expression of Tobacco mosaic virus (TMV) symptoms on tobacco leaves treated with cyanobacterias or algae was investigated. When tobacco plants were treated two days before the inoculation, it was verified that the cells suspensions from strains 004/02, 008/02, Anabaena sp., and Nostoc sp. 61 of cyanobacteria and strain $061 / 02$ of alga as well as the preparations of

the intracellular content from 004/02 strain (4 C) and the medium filtrated from 061/02 strain (61 M) reduced the number of local lesions caused by TMV on tobacco leaves, cultivar TNN. Furthermore, it was also verified that Anabaena sp., Nostoc sp. 21 (cyanobacteria), Nostoc sp. 61 and 090/02 (alga) strains showed direct effects on the semipurified virus. Therefore, it is suggested that the cyanobacterias and the algae studied produce compounds that can show direct effects on TMV and/or activate the defense mechanisms of the plants.
\end{abstract}

Keywords: biological control and induced resistance.

As cianobactérias, juntamente com as algas, compreendem a maior parte da biomassa do mundo (6). Sua ocorrência abrange um espectro ambiental muito variado envolvendo solos, água doce e salgada, áreas onde a temperatura é muito alta (superior a $60^{\circ} \mathrm{C}$ ) e/ou extremamente áridas (que não comporta o desenvolvimento de outros grupos biológicos). Essa versatilidade é devida em grande parte a capacidade que as cianobactérias exibem de fixar nitrogênio e realizar fotossíntese (25). Além disso, as cianobactérias possuem estrutura celular típicas de bactérias Gram-negativas, bem como morfologia muito variada (25). As algas, por sua vez, são fotoautotróficas, porém algumas espécies podem crescer de maneira heterotrófica. Visto que todas as células das algas fazem fotossíntese e são capazes de absorver nutrientes, as mesmas não precisam de sistemas de vasos. As algas podem ser unicelulares ou multicelulares. O corpo é formado por um talo, que fixa a alga em um suporte, uma estrutura caulinifome, que não é lignificada ou lenhosa e por lâminas que se assemelham a folhas (27).

As cianobactérias e algas produzem uma grande quantidade de compostos biologicamente ativos, os quais podem apresentar propriedades farmacológicas $(5,21)$, efeitos adversos sobre animais $(14,24)$ e seres humanos $(8,13)$, bem como apresentar atividades antibacteriana (17), antifúngica (16) e com ação direta sobre vírus (9).

A aplicação em sementes de extrato de etil acetato da cianobactéria Calothrix elenkenii reduziu a mortalidade de plântulas de tomate, pimentão e berinjela provocada por Pythium aphanidermatum (16). Filtrados de diversas espécies de cianobactérias reduziram o crescimento micelial e a esporulação de Fusarium verticellioides, Sclerotium rolfsii e Rhizoctonia solani (19). Além disso, o extrato da alga Ulva spp. reduziu os sintomas provocados por Colletotrichum trifolii em folhas de Medicago truncatula (7).

Pandey \& Pandey (17) verificaram que extratos etanólicos 
das cianobactérias Lyngbya majuscula, Microcystis aeruginosa e Plectonema boryanum, além de terem reduzido o crescimento in vitro de Xanthomonas vesicatoria, também reduziram em pelo menos $85 \%$ o número de lesões provocadas por essa bactéria em pimentão. Por sua vez, extratos metanólicos de várias espécies de Laurencia apresentaram efeito in vitro sobre Erwinia amylovora (28).

Di Piero et al. (9), por sua vez, demonstraram que filtrados de culturas e os conteúdos intracelulares das cianobactérias Synechococcus leopoliensis e Nostoc sp. reduziram em pelo menos $50 \%$ a quantidade de lesões provocadas pelo TMV em plantas de fumo, cultivar TNN.

Por outro lado, alguns trabalhos $(2,3,10)$ mostraram que as cianobactérias e algas podem induzir a síntese de fitoalexinas, que são compostos que apresentam baixo peso molecular e são produzidas pelas plantas em resposta a infecção ou estresse (4).

Em vista do exposto, o objetivo deste trabalho foi verificar o efeito de diversos isolados de cianobactérias e de algas na manifestação dos sintomas causados por TMV em plantas de fumo.

\section{MATERIAL E MÉDODOS}

\section{Cultivo e manutenção das algas}

Os isolados das cianobactérias e das algas da coleção do Laboratório de Fisiologia e Bioquímica Fitopatológica, do Setor de Fitopatologia (ESALQ/USP), foram utilizados para a realização dos experimentos. Além disso, usou-se os isolados das cianobactérias Nostoc sp. $21 \mathrm{e}$ Nostoc sp. 61, cedidos pela Dr ${ }^{\mathrm{a}}$ Marly F. Fiori (CENA/USP, Piracicaba, $\mathrm{SP})$.

O cultivo foi efetuado em frascos tipo erlenmeyer de $250 \mathrm{~mL}$, os quais continham $100 \mathrm{~mL}$ de meio de cultura BG 11 (1). A repicagem periódica foi efetuada com a adição de uma alíquota de $1 \mathrm{~mL}$ de inóculo por recipiente. Os isolados foram mantidos a $28{ }^{\circ} \mathrm{C}$, sob luz fluorescente constante.

Para verificar se os organismos utilizados como agentes de biocontrole eram eucariotos ou procariotos, os mesmos foram cultivados em meio de cultura com $10 \mathrm{mg} \mathrm{L}^{-1}$ de cicloheximida, a qual inibe a síntese de proteínas de eucariotos.

A biomassa foi quantificada com a filtragem de $10 \mathrm{~mL}$ de suspensão dos isolados em filtros tipo GF/A, cujos pesos foram previamente determinados. Após, os filtros foram mantidos em estufa a $60{ }^{\circ} \mathrm{C}$ por 48 $\mathrm{h}$ e foram novamente pesados. A quantificação do peso da matéria seca foi feita com base na diferença da segunda para a primeira pesagem.

\section{Obtenção dos preparados das algas e cianobactérias}

A obtenção dos preparados dos isolados foi conduzida de acordo com a metodologia descrita por Di Piero et al. (9). Alíquotas de $75 \mathrm{~mL}$ de "suspensões de células" (S) das culturas (20 dias após a repicagem) sofreram uma filtragem a vácuo através de filtro tipo GF/A, seguida de outra filtragem a vácuo por membrana tipo Millipore (diâmetro de 0,2 $\mathrm{mm}$ ), obtendo-se o "filtrado do meio de cultivo" (M). Por sua vez, as células que ficaram retidas na filtragem das culturas foram colocadas em almofariz e trituradas com pistilo, com a adição de nitrogênio líquido. $\mathrm{O}$ pó obtido foi ressuspenso em $10 \mathrm{~mL}$ de água destilada e as suspensões resultantes centrifugadas a $10.000 \mathrm{~g}$ por $10 \mathrm{~min}$, seguida por filtragem a vácuo do sobrenadante, com o uso de membrana tipo Millipore, obtendo-se assim o "filtrado do conteúdo intracelular" (C).

Obtenção e manutenção do TMV

O isolado do vírus, cedido pelo Prof. Dr. Robson M. Di Piero (UFSC, Florianópolis), foi inoculado mecanicamente em plantas sadias de fumo, cultivar Turkish (onde a infecção é sistêmica), com 40 dias de cultivo, mantidas sob condições de casa-de-vegetação e cultivas em vasos de alumínio, com volume de $1840 \mathrm{~cm}^{3}$, que continham mistura autoclavada de terra, areia e matéria orgânica (3:1:1; v/v/v, respectivamente). Após 25 dias da inoculação das plantas, as folhas que exibiam sintoma de mosaico foram coletadas, pesadas, congeladas e, a partir dessas, feita a purificação parcial de partículas vírais, de acordo com Sherwood \& Fulton (23). A concentração do vírus foi calculada utilizando-se a fórmula: $\mathrm{c}=$ Abs $(260 \mathrm{~nm}) / \mathrm{e}$, onde "c" é a concentração do vírus em $\mathrm{mg} \mathrm{mL}^{-1}$ e "e" o coeficiente de extinção do TMV, que equivale a 3,1 de absorbância para cada $\mathrm{mg} \mathrm{mL}^{-1}$ de vírus. Após sua quantificação, o vírus parcialmente purificado foi distribuído em tubos tipo eppendorf (alíquotas de $100 \mu \mathrm{L}$ ), as quais foram mantidos a $-20^{\circ} \mathrm{C}$.

Efeito das suspensões celulares e das preparações (conteúdo intracelular e filtrado do meio de cultivo) das cianobactérias e das algas na manifestação dos sintomas provocados por TMV

Plantas de fumo, cultivar TNN, com 40 dias de idade, mantidas sob condições de casa-de-vegetação, cultivadas em vasos de alumínio, com volume de $1840 \mathrm{~cm}^{3}$, que continham mistura autoclavada de terra, areia e matéria orgânica $(3: 1: 1$; $\mathrm{v} / \mathrm{v} / \mathrm{v}$, respectivamente), foram tratadas, pincelando-se meiafolha intermediária, com as suspensões de células (S) ou com as preparações do meio de cultivo (M) ou do conteúdo intracelular (C) dos isolados 004/02, 008/02, 061/02, 090/02, Anabaena sp., Nostoc sp. 21 ou Nostoc sp. 61 (20 dias após a repicagem). Como controles foram utilizados acibenzolar-S-metílico (ASM) $\left(50 \mathrm{mg} \mathrm{mL}^{-1}\right.$ i.a.), água destilada ou meio de cultura BG 11. A outra meia-folha, bem como a folha imediatamente superior e a inferior à tratada, foram tratadas com água destilada (Figura 1). Após 2 dias, as 3 folhas previamente tratadas foram inoculadas mecanicamente com TMV ( $20 \mu \mathrm{g}$ de vírus $\mathrm{mL}^{-1}$ de tampão fosfato de potássio $20 \mathrm{mM}, \mathrm{pH} 7$ ). A avaliação foi realizada 5 dias após a inoculação do fitopatógeno, com base na contagem do número de lesões locais. Cada tratamento foi composto por 3 repetições. A análise estatística foi efetuada com o uso do teste de Tukey $5 \%$, sendo que o experimento foi repetido duas vezes.

Meia folha tratada com água destilada (Figuras 4 e 5)

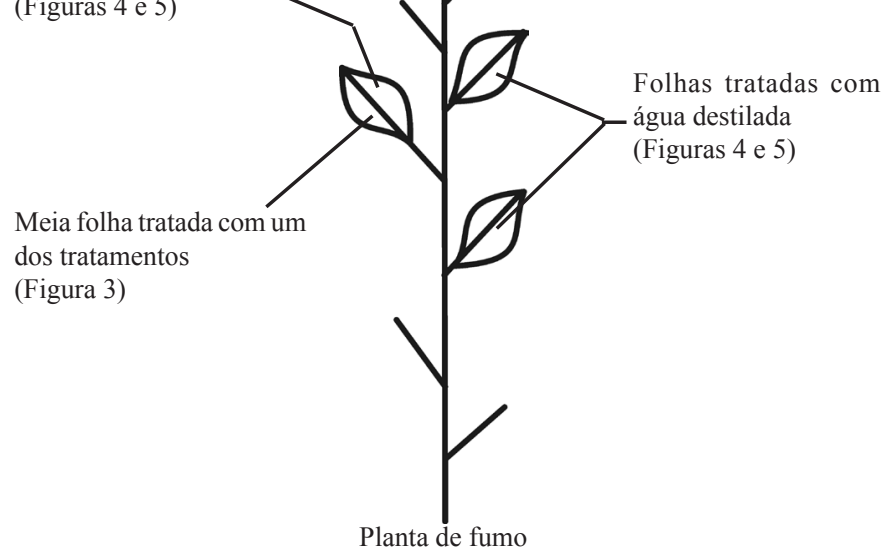

Figura 1. Esquema utilizado para os testes de verificação dos efeitos local e sistêmico dos isolados de algas e cianobactérias na redução do número de lesões locais, em plantas de fumo, provocadas pelo TMV. 
Efeito inibitório das cianobactérias e das algas sobre o TMV

Suspensões de células (S) dos isolados 004/02, 008/02, 061/02, 090/02, Anabaena sp., Nostoc sp. 21 e Nostoc sp. 61, além dos controles água destilada, meio de cultura BG 11 e ASM $\left(50 \mathrm{mg} \mathrm{mL}^{-1}\right.$ i.a.) foram misturadas com suspensão das partículas virais parcialmete purificadas (40 $\mu \mathrm{g}$ de vírus $\mathrm{mL}^{-1}$ de tampão fosfato de potássio $20 \mathrm{mM}, \mathrm{pH}$ 7) (1:1; $\mathrm{v} / \mathrm{v})$. A seguir, as plantas de fumo, com 40 dias de cultivo, mantidas sob condições de casa-de-vegetação, foram inoculadas, mecanicamente, em uma folha intermediária com uma das preparações. A avaliação foi realizada 5 dias após a inoculação, com base na contagem do número de lesões locais. Cada tratamento foi composto por 3 repetições. A análise estatística foi efetuada com o uso do teste de Tukey $5 \%$, sendo que experimento foi repetido duas vezes.

\section{RESULTADOS E DISCUSSÃO}

Os isolados 004/02, Anabaena sp., Nostoc sp. 21 e Nostoc sp. 61 cresceram em meio de cultura BG 11 que continha cicloheximida (10 $\mathrm{mg} \mathrm{mL}^{-1}$ ), portanto os mesmos podem ser considerados cianobactérias. Por sua vez, os isolados 008/02, 061/02 e 090/02 não cresceram, evidenciando que os mesmos eram algas (dados não mostrados).

Na Figura 2, pode-se observar que os isolados 004/02 e Nostoc sp. 21 apresentaram maior peso de matéria seca do que os demais isolados.

Quanto aos testes realizados para se verificar a redução dos sintomas de TMV em folhas de plantas de fumo, pode-se observar na Figura 3 A, que as suspensões de células (S) dos isolados 004/02, 008/02, 061/02 Anabaena sp. e Nostoc sp. 61 apresentaram efeito na

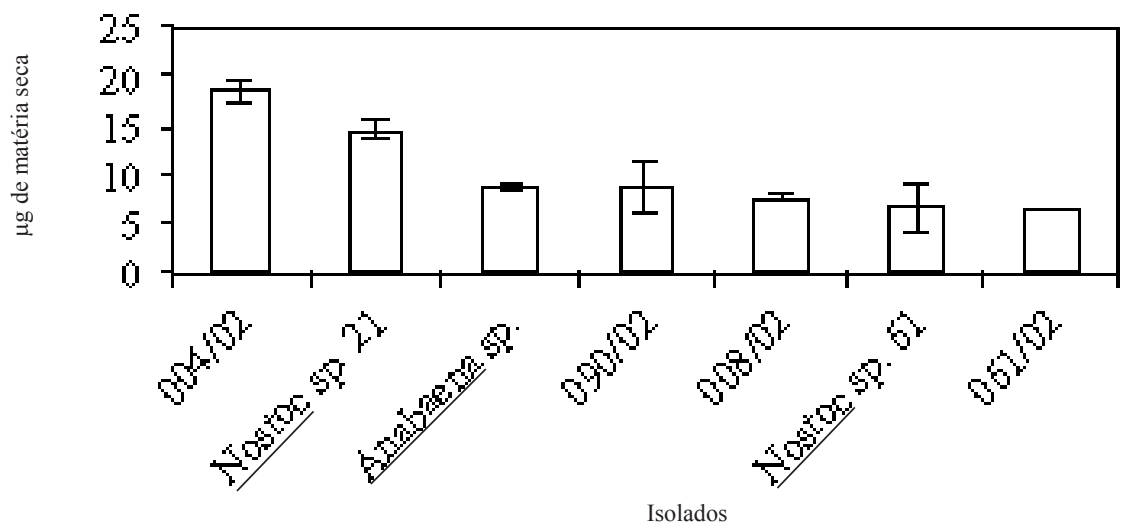

Figura 2. Quantificação do peso da matéria seca dos isolados de algas e cianobactérias. As barras representam a média \pm desvio padrão.
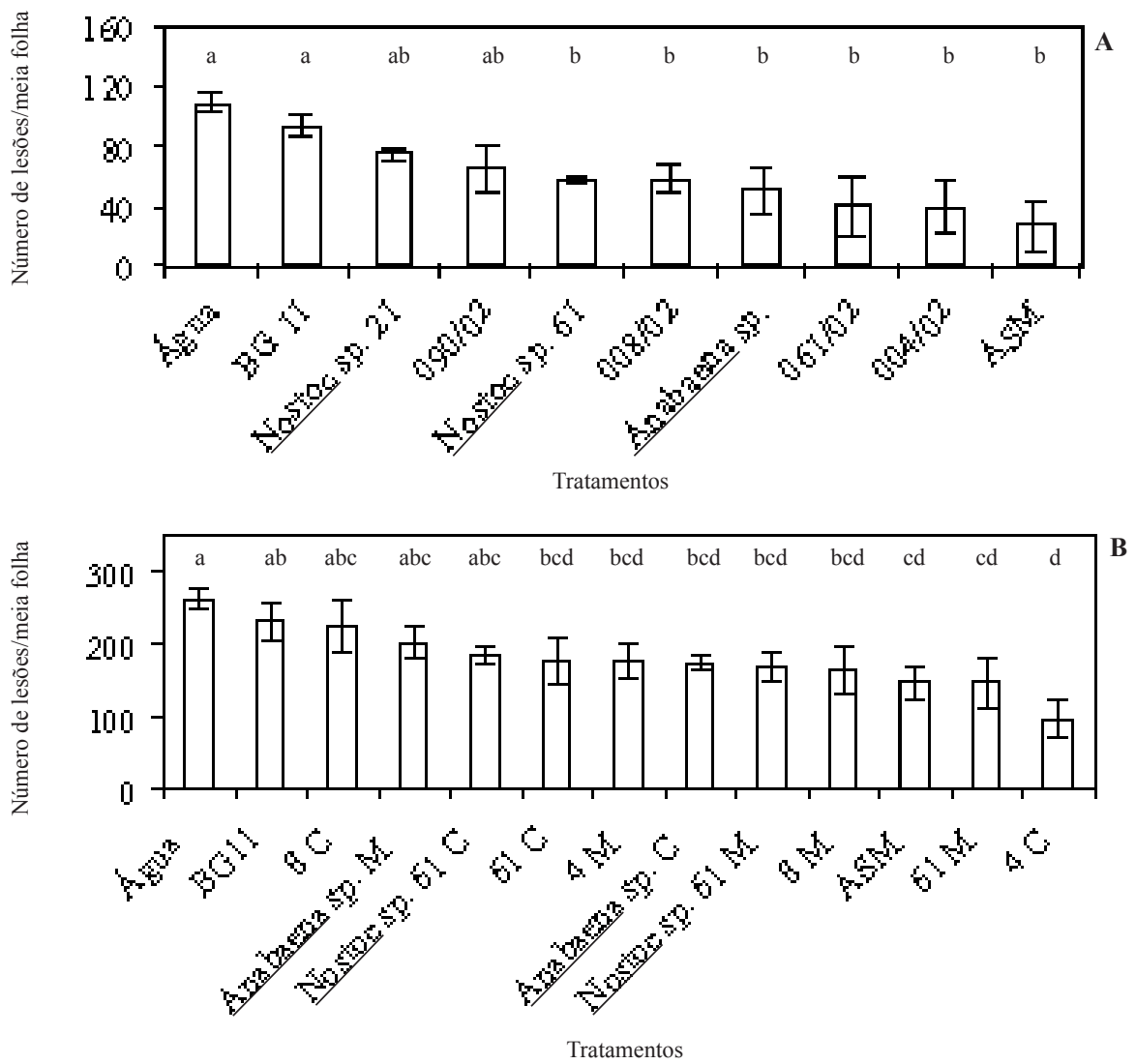

Figura 3. Influência local das suspensões de células (S) dos isolados (A) e das preparações (C e M) (B) de algas e cianobactérias na redução dos sintomas causados pelo TMV em plantas de fumo, cultivar TNN. As barras representam a média \pm desvio padrão. Médias seguidas por letras iguais não diferem entre si pelo teste de Tukey 5\%. ASM = acibenzolar-S-metílico; BG11 = meio de cultura; $\mathrm{C}=$ filtrado do meio de cultivo; $\mathrm{M}=$ conteúdo intracelular. 

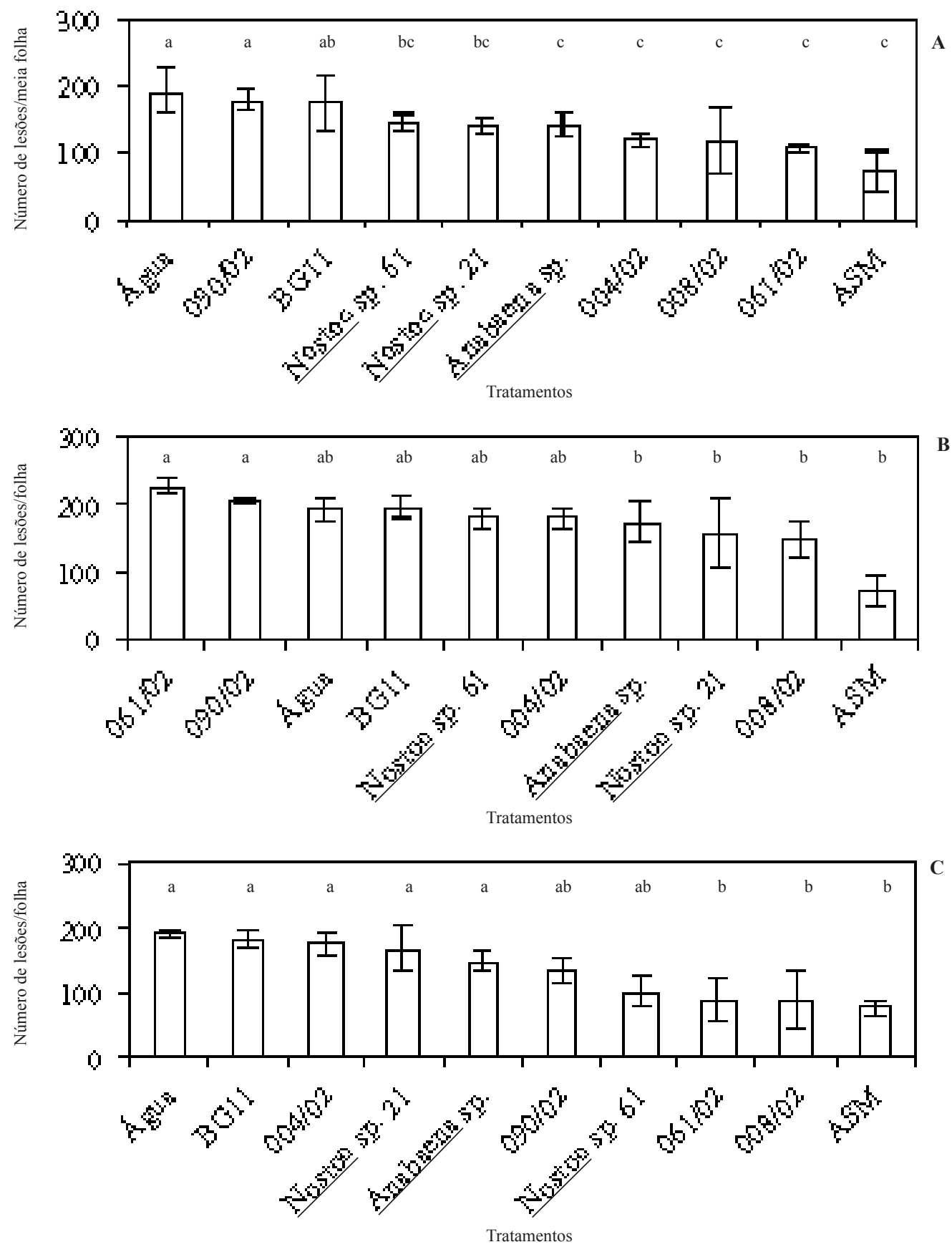

Figura 4. Influência sistêmica das suspensões de células (S) dos isolados de algas e cianobactérias na redução dos sintomas causados pelo TMV, inoculado mecanicamente em folhas de plantas de fumo, cultivar TNN. As barras representam as médias \pm desvio padrão. Médias seguidas por letras iguais não diferem entre si pelo teste de Tukey $5 \%$. A = vírus inoculado nas meia folhas não tratadas; $\mathrm{B}=$ vírus inoculados nas folhas superiores às tratadas; $\mathrm{C}=$ vírus inoculado nas folhas inferiores às tratadas. ASM = acibenzolar-S-metílico; BG11 = meio de cultura.

redução do número de lesões locais. Essa redução foi estatisticamente semelhante à ocasionada pelo ASM. Por outro lado, o meio de cultivo BG 11 foi semelhante à água. Quando as plantas de fumo foram tratadas previamente com as preparações, $\mathrm{C}$ ou $\mathrm{M}$, apenas os filtrados do meio de cultivo do isolado 061/02 (61 M) e do conteúdo intracelular do isolado 004/02 (4 C) reduziram o número de lesões locais provocadas por TMV em folhas de plantas de fumo (Figura 3 B). Essa redução foi estatisticamente semelhante à ocasionada pelo ASM.

Na Figura 4 A, pode-se observar que as suspensões de células (S) dos isolados 004/02, 008/02, 061/02 e Anabaena sp. apresentaram efeito sistêmico na meia folha tratada com água destilada. Além disso, nenhuma suspensões de células (S) reduziu o número de lesões locais provocadas por TMV nas folhas de plantas de fumo superiores às tratadas (Figura 4 B). Por fim, apenas os isolados 008/02 e 061/02 reduziram o número médio de lesões locais provocadas por TMV nas folhas de plantas fumo inferiores a tratadas com as suspensões de células (S) (Figura $4 \mathrm{C}$ ).

Por outro lado, nenhuma das preparações reduziu de maneira 

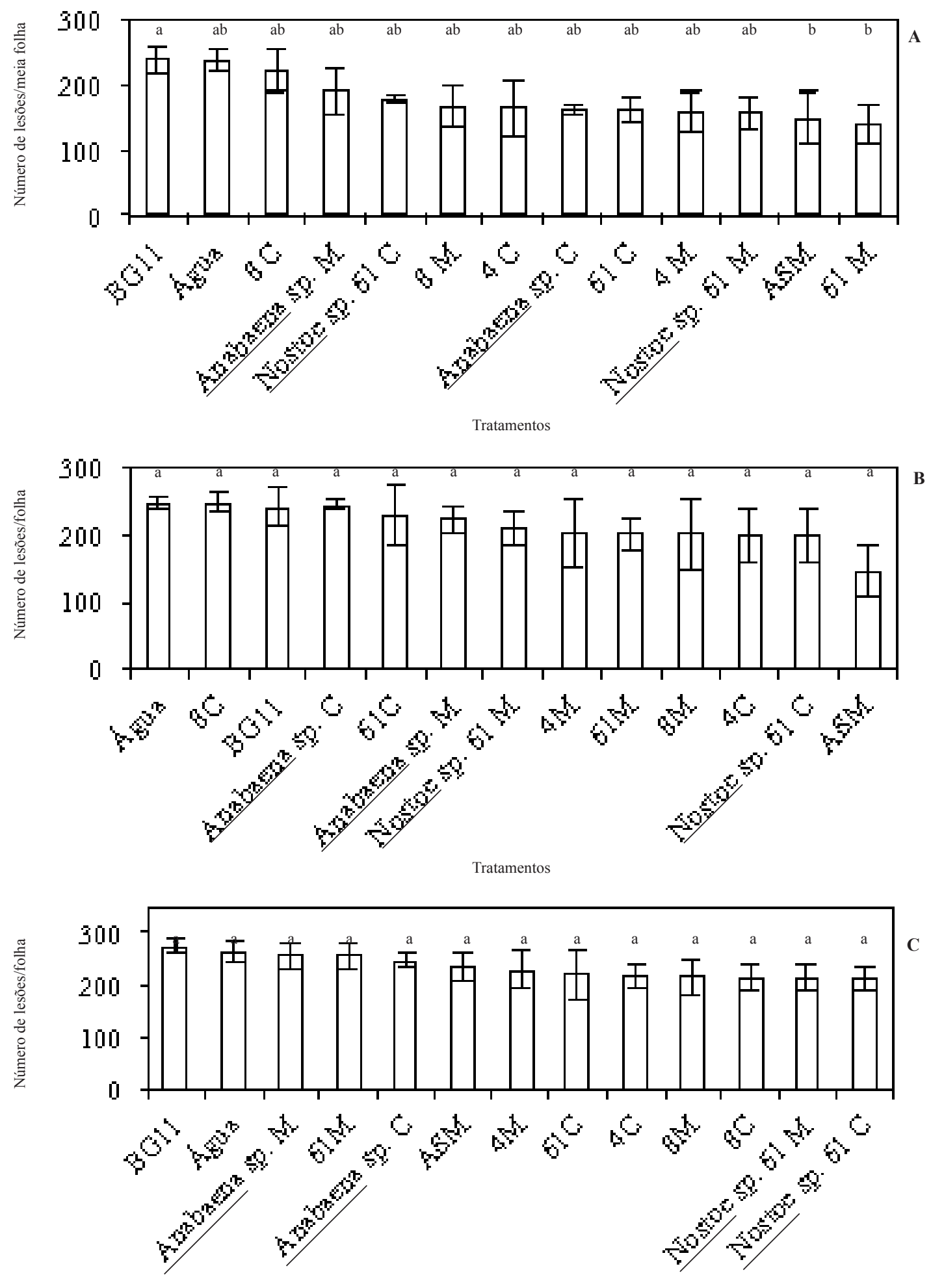

Tratamentos

Figura 5. Influência sistêmica das preparações $\mathrm{C}$ e $\mathrm{M}$ de algas e cianobactérias na redução dos sintomas causados pelo TMV, inoculado mecanicamente em folhas de plantas de fumo, cultivar TNN. As barras representam as médias \pm desvio padrão. Médias seguidas por letras iguais não diferem entre si pelo teste de Tukey $5 \%$. $\mathrm{A}=$ vírus inoculado nas meia folhas não tratadas; $\mathrm{B}=$ vírus inoculados nas folhas superiores às tratadas; $\mathrm{C}=$ vírus inoculado nas folhas inferiores às tratadas. $\mathrm{ASM}$ = acibenzolar-S-metílico; BG11 = meio de cultura; $\mathrm{C}=$ preparação do conteúdo intracelular; $\mathrm{M}=$ preparação do filtrado do meio de cultivo. 


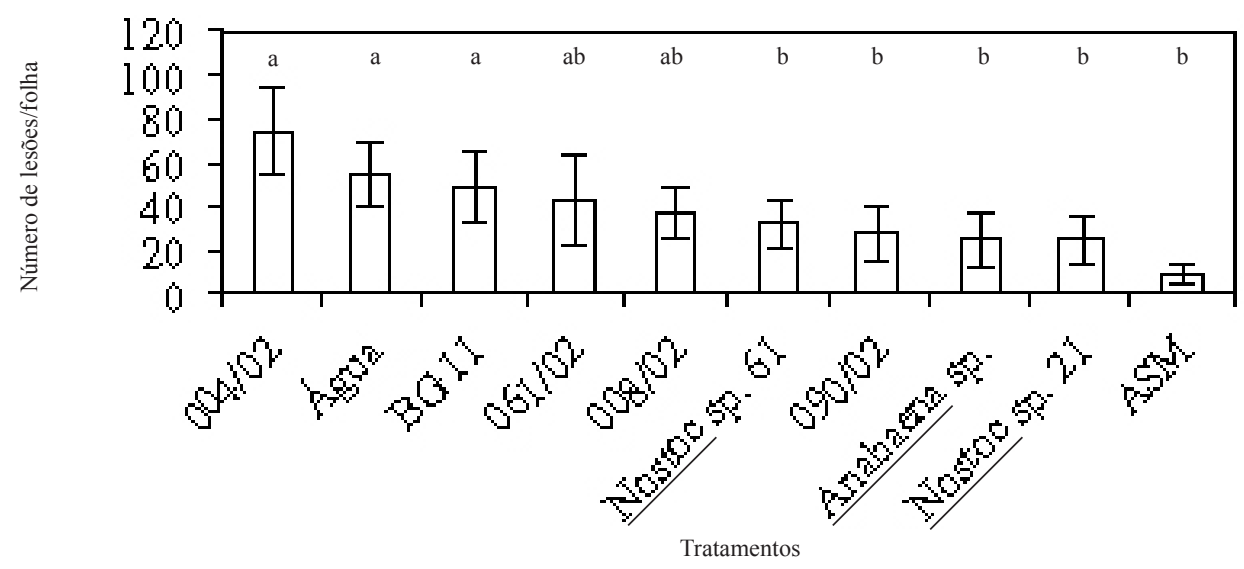

Figura 6. Efeito inibitório das suspensões de células (S) dos isolados de algas e cianobactérias sobre o TMV (inoculo viral misturado com as S), inoculado mecanicamente, em plantas de fumo, cultivar TNN. As barras representam as médias \pm desvio padrão. Médias seguidas por letras iguais não diferem entre si pelo teste de Tukey $5 \%$. ASM = acibenzolar-S-metílico; BG11 = meio de cultura.

sistêmica o número de lesões locais na interação estudada (Figura 5).

Finalmente, como pode ser visto na Figura 6, o número de lesões locais provocadas por TMV em folhas plantas de fumo, ressuspenso com as suspensões de células (S) dos isolados 090/02, Anabaena sp., Nostoc sp. 21 ou Nostoc sp. 61, foi menor do que o número de lesões locais em folhas inoculadas com o TMV ressuspenso em água destilada ou meio de cultura BG 11.

Zainuddin et al. (30) mostraram que os extratos metanólicos das cianobactérias Calothrix gracilis, Lyngbya sp., Microecystis ichthyoblabe, Nodularia spumigena, Oscillatoria lutae e Seytonema bohnerii, bem como o extrato aquoso de N. spumigena, apresentaram atividade antiviral in vitro sobre o vírus influenza A. Por sua vez, sacarídeos extraídos de Cryptonemia crenulatara inibiram o Dengue virus (DENV) (26). Extratos de Undaria pinnatiûda, Splachnidium rugosum, Gigartina atropurpurea e Plocamium cartilagineum apresentaram efeito inibitório sobre Herpes simplex virus tipo $1 \mathrm{e}$ 2 (HSV-1 e HSV-2) (12). Em busca de melhorar o conhecimento científico no controle da Síndrome da Imunodeficiência Adquirida (AIDS), diversos pesquisadores têm estudado compostos isolados de diferentes gêneros de cianobactérias e algas, como sacarídeos extraídos de Grateloupia ûlicina e Grateloupia longifolia (29) Oscillatoria agardhii (22) e Spatoglossum schröederi (18), os quais apresentaram efeito inibitório sobre o Human immunodeficiency virus (HIV).

Di Piero et al. (9) mostraram que suspensões celulares de $S$. leopoliensis e Nostoc sp., bem como preparações dos conteúdos intracelulares e dos meios de cultivos, com 30, 60 ou 140 dias de cultivo, apresentaram efeito local na redução dos sintomas provocados por TMV em folhas de plantas de fumo. Porém, apenas a suspensão celular da Nostoc sp., com 140 dias, proporcionou efeito sistêmico. A aplicação de oligossacarídeos extraídos de alga Lessonia vadosa reduziu o número de lesões provocadas por TMV em fumo, bem como estimulou a atividade de enzimas antioxidantes (15). De acordo com Galal \& Al-Turk (11), extratos de várias espécies de algas apresentaram efeito inibitório sobre o Cucumber mosaic virus (CMV), bem como ativaram os mecanismos de defesa de plantas de pepino, que provocou redução dos sintomas do CMV.

A aparente falta de efeito direto dos isolados 004/02, 008/02 e 061/02 sobre as partículas virais do TMV e o intervalo de tempo necessário, entre o tratamento das plantas e a inoculação do vírus para que as plantas de fumo tivessem os sintomas reduzidos, sugerem que os mecanismos de defesa das plantas foram ativados por esses tratamentos (20). Já os isolados Nostoc sp. 21 e 090/02 apresentaram compostos que agem diretamente sobre o patógeno. Finalmente, os isolados Anabaena sp. e Nostoc sp. 61 apresentaram compostos que agem diretamente sobre o vírus, além de, possivelmente, induzirem os mecanismo de defesa das plantas de fumo.

Em vista disso, pode-se concluir que as algas e as cianobactérias estudadas podem apresentar efeito inibitório direto sobre o TMV, bem como ativar mecanismos de defesa vegetal contra fitopatógenos.

\section{REFERÊNCIAS BIBLIOGRÁFICAS}

1. Allen, M.M. Simple conditions for growth of unicellular blue-green algae on plates. Journal of Phycology. Lawarence, v. 4, p. 1-4, 1968.

2. Bi, F.; Arman, M.; Ali, A.; Seema, I. Phytoalexins induced in Cicer arietinum characterized by LC-MS technique. Indian Journal of Plant Physiology. New Delhi, v. 14, p. 1-6, 2009.

3. Bi, F.; Iqbal, S.; Ali, A.; Arman; M.; Hassan, M.U. Induction of secondary metabolites in chickpea, pea, carrot and potato tissues in response to elicitor of Hypnea musciformis. Indian Journal of Plant Physiology. New Delhi, v. 14, p. 101-106, 2008.

4. Braga, M.R. Fitoalexinas. In: Pascholati, S.F.; Leite. B.; Stangarlin, J.R.; Cia, P. (Ed.) Interação Planta-Patógeno: Fisiologia, Bioquímica e Biologia Molecular. Piracicaba: FEALQ, 2008. cap. 5, p. 305-346.

5. Burja, M.A.; Banaigs, B.; Abou-Mansou, R.E.; Burgess, J.G.; Wright, P.C. Marine cyanobacteria - a prolific source of natural products. Tetraedron. Oxford, UK, v. 57, n. 46, p. 9347-9377, 2001.

6. Cannel, R. J. P. Algae as a source of biologically active products. Pesticide Science, London, v. 39, p. 147-153, 1993.

7. Cluzet, S.; Torregrosa, C.; Jacquet, C.; Lafitte, C.; Fournier, J.; Mercier, L.; Salamagne, S.; Briand, X.; Esquerré-Tugayé, M.T.; Dumas, B. Gene expression proûling and protection of Medicago truncatula against a fungal infection in response to an elicitor from green algae Ulva spp. Plant, Cell and Environment. Nottinghan, v. 27, p. 917-928, 2004.

8. Cox, P.A.; Baback, S.A.; Murch, S. Biomagnification of cyanobacterial neurotoxins and neurodegenerative disease among Chamorro people of Guam. Proceedings of the National Academy of Sciences of The United States of America. Washinhton, v. 100, n. 23, p. 13380-13383, 2003.

9. Di Piero, R.M.; Pascholati, S.F.; Rezende, J.A.M. Efeito das cianobactérias Synechococcus leopoliensis e Nostoc sp. na infectividade do vírus do mosaico do fumo (TMV). Summa Phytopathologica. Jaboticabal, v. 26, p. 261-266, 2000.

10. Di Piero, R.M.; Pascholati, S.F. Efeito das cianobactérias Synechococcus leopoliensis e Nostoc sp. sobre Colletotrichum sublineolum e na interação 
do patógeno com plantas de sorgo. Fitopatologia Brasileira. Fortaleza, v. 27, p. 163-169, 2002.

11. Galal, A.-M.M.; Al-Turk, I.M. Antiphytoviral potentialities of algal extracts against Cucumber mosaic virus. Journal of Pure \& Applied Microbiology. Bhopal, v. 2, p. 85-90, 2008.

12. Harden, E.A.; Falshaw, R.; Carnachan, S.M.; Kern, E.R.; Prichard, M.N. Virucidal activity of polysaccharide extracts from four species against herpes simplex virus. Antiviral Research. Amsterdam, v. 83, p. 282-289, 2009.

13. Jonasson, S.; Eriksson, J.; Berntzon, L.; Spáèil. Z.; Ilag, L.L.; Ronnevi, L.-O.; Rasmussen, U.; Bergman, B. Transfer of a cyanobacterial neurotoxin within a temperate aquatic ecosystem suggests pathways for human exposure. Proceedings of the National Academy of Sciences of The United States of America. Washinhton, v.107, p. 9252-9257, 2010.

14. Lance, E.; Josso, C.; Dietrich, D.; Ernst, B.; Paty, C.; Senger, F.; Bormans, M.; Gérard, C. Histopathology and microcystin distribution in Lymnaea stagnalis (Gastropoda) following toxic cyanobacterial or dissolved microcystin-LR exposure. Aquatic Toxicology. Amsterdam, v. 98, p. 211-220, 2010.

15. Laporte, D.; Vera, J.; Chandía, N.P.; Zúñiga, E.A; Matsuhiro, B.; Moenne, A. Structurally unrelated algal oligosaccharides differentially stimulate growth and defense against tobacco mosaic virus in tobacco plants. Journal of Applied Phycology. Dordrecht, v.19, p. 79-88, 2007.

16. Manjunath, M.; Prasanna, R.; Nain, L.; Dureja, P.; Singh, R.; Kumar, A.; Jaggi, S.; Kaushi, B.D. Biocontrol potential of cyanobacterial metabolites against damping off disease caused by Pythium aphanidermatum in solanaceous vegetables. Archives of Phytopathology and Plant Protection. Abindgon, v. 43, p. 666-677, 2010.

17. Pandey, U.; Pandey, J. Antibacterial properties of cyanobacteria: A cost-effective and eco-friendly approach to control bacterial leaf spot disease of chilli. Current Science. Bangalore, v. 82, n. 3, p. 262-264, 2002.

18. Queiroz, K.C.C.; Medeiros, V.P.; Queiroz, L.S.; Abreu, L.R.D.; Rocha, H.A.O.; Ferreira, C.V.; Jucá, M.B.; Aoyama, H.; Leite, E.L. Inhibition of reverse transcriptase activity of HIV by polysaccharides of brown algae. Biomedicine \& Pharmacotherapy. Paris, v. 68, p. 303-307, 2008.

19. Rizk, M.A. Growth activities of the sugarbeet pathogens Sclerotium rolfsii Sacc., Rhizoctonia solani Khun. and Fusarium verticillioides Sacc. under cyanobacterial filtrates stress. Plant Pathology Journal. Suwon, v. 5, p.
212-215, 2006.

20. Romeiro. Indução de resistência em plantas a patógenos. In: Pascholati, S.F.; Leite. B.; Stangarlin, J.R.; Cia, P. (Ed.) Interação Planta-Patógeno: Fisiologia, Bioquímica e Biologia Molecular. Piracicaba: FEALQ, 2008. cap. 13, p. 411-431

21. Sainis, I.; Fokas, D.; Vareli, K.; Tzakos, A.G.; Kounnis, V.; Briasoulis, E. Cyanobacterial cyclopeptides as lead compounds to novel target cancer drugs. Marine Drugs. Basel, v. 8, p. 6290-657, 2010.

22. Sato, Y.; Okuyama, S.; Hori, K. Primary structure and carbohydrate binding specificity of a potent anti-HIV lectin isolated from the filamentous cyanobacterium Oscillatoria agardhii. The Journal of Biological Chemistry. Bethesda, v. 282, p. 11021-11029, 2007.

23. Sherwood, J.L.; Fulton, R.W. The specifc involvement of coat protein in tobacco mosaic virus cross protection. Virology. San Diego, v. 60, n. 12, p. 1251-1260, 1982.

24. Soares, R.M.; Magalhães, V.F.; Azevedo, S.M.F.O. Accumulation and depuration of microcystins (cyanobacteria hepatotoxins) in Tilapia redalli (Cichidae) under laboratory conditions. Aquatic Toxicology. Amsterdam, v. 70, n. 1, 1-10, 2004.

25. Stanier, R.Y.; Cohen-bazire, G. Phototrophic prokaryotes: The cyanobacteria. Annual Review of Microbiology. Palo Alto, v. 31, p. 225-274, 1977.

26. Talarico, L.B.; Duarte, M.E.R.; Zibetti, R.G.M.; Nosela, M.D.; Damonte, E.B. An algal-derived DL-galactan hybrid is efficient preventing agent for in vitro Dengue virus infection. Planta Medica. Stuttgart, v. 73, p. 1464-1468, 2007

27. Tortora, G.J.; Funke. B.R.; Case, C.L. Microbiologia. Porto Alegre: Artmed, 2005. 920p.

28. Vairappan, C.S.; Suzukia, M.; Abeb, T.; Masudac, M. Halogenated metabolites with antibacterial activity from the Okinawan Laurencia species. Phytochemistry. Oxford, UK, v. 58, p. 517-523, 2001.

29. Wang, S.C.; Bligh, S.W.A.; Shi, S.S.; Wang, Z.T.; Hu, Z.B.; Croder, J.; Bradforf-White, C.; Vella, C. Structural features and ant-HIV-1 activity of novel polysaccharides from red algae Grateloupia longifolia and Grateloupia ûlicina. International Journal of Biological Macromolecules. Amsterdam, v. 41, p. 369-375, 2007. 